\title{
Evaluation of the effects of group psychotherapy on cognitive function in patients with multiple sclerosis with cognitive dysfunction and depression
}

\author{
Avaliação do efeito da psicoterapia de grupo sobre as funções cognitivas de pacientes \\ com esclerose múltipla que apresentam simultaneamente alterações cognitivas e \\ depressão
}

Emine Bilgi ${ }^{1}$, Hasan Hüseyin Özdemir ${ }^{2}$, Ayhan Bingol' ${ }^{3}$, Serpil Bulut ${ }^{4}$

\begin{abstract}
Objective: This study will evaluate how decreasing depression severity via group psychotherapy affects the cognitive function of patients with multiple sclerosis (MS) who are also diagnosed with depression and cognitive dysfunction. Method: MS patients completed the Brief Repeatable Battery of Neuropsychological Tests and Beck Depression Inventory (BDI). The group members diagnosed with depression and cognitive dysfunction underwent group psychotherapy for 3 months. Upon completion of psychotherapy, both tests were readministered. Results: Depression and cognitive dysfunction were comorbid in 15 (13.9\%) of patients. Although improvement was detected at the end of the 3-month group psychotherapy intervention, it was limited to the BDI and the Paced Auditory Test. Conclusion: Group psychotherapy might decrease cognitive impairment in MS patients.
\end{abstract}

Keywords: multiple sclerosis, group psychotherapy, cognitive functions, cognitive dysfunction, depression.

\section{RESUMO}

Objetivo: Avaliar como a melhora da depressão grave através da psicoterapia afeta a função cognitiva de pacientes com esclerose múltipla (EM) diagnosticados com depressão e disfunção cognitiva. Método: Foram aplicados a pacientes com EM o "Brief Repeatable Battery of Neuropsychological Test” e o Inventário de depressão de beck (BDI). Os pacientes com depressão e disfunção cognitiva foram submetidos a psicoterapia de grupo por 3 meses. Depois desse período, foram reaplicados os mesmos testes. Resultados: Depressão e disfunção cognitiva foram detectadas conjuntamente em 15 (13,9\%) dos pacientes. Embora os pacientes se tivessem recuperado ao fim dos 3 meses de psicoterapia de grupo, somente através do BDI e do "Paced Auditory Test" foi possível detectar uma recuperação significativa. Conclusão: Psicoterapia de grupo pode diminuir o comprometimento cognitivo em pacientes com EM.

Palavras-chave: esclerose múltipla, psicoterapia de grupo, funções cognitivas, disfunção cognitiva, depressão.

Multiple sclerosis (MS) is a chronic inflammatory disease considered to be of autoimmune origin and characterized by focal inflammatory-demyelinating lesions, neuroinflammation, and neurodegeneration of the central nervous system (CNS), affecting the white matter, cortex and deep gray matter of the brain ${ }^{1}$. The demyelination associated with MS lesions and axonal degeneration is responsible for neurological disabilities in patients with $\mathrm{MS}^{1}$.

One or more psychiatric symptoms, including anxiety and depression, are observed in approximately $80 \%$ of individuals with $\mathrm{MS}^{2,3}$. Schiffer noted that a high incidence and prevalence of depressive symptoms have been reported in MS compared to many other neurological diseases ${ }^{4}$.

Assessments with neuropsychological tests can identify the presence of cognitive dysfunction in $65 \%$ of patients with MS, compared to only $5 \%$ of outpatient controls ${ }^{5}$. Cognitive dysfunction, independent of the physical disability created by the disease itself, is an important factor that impairs routine daily activities and decreases labor productivity ${ }^{6,7,8}$. Cognitive disorders observed in MS usually affect memory,

\footnotetext{
'Department of Neurology, Diskapi Yildirim Beyazit Training and Research Hospital, Ankara, Turkey;

2Department of Neurology, Dicle University Medical School Hospital, Diyarbakir, Turkey;

${ }^{3}$ Mayis Psychology Center, Istanbul, Turkey;

${ }^{4}$ Firat University Faculty of Medicine, Elazig, Turkey.

Correspondence: Emine Bilgi; Department of Neurology, Diskapi Yildirim Beyazit Training and Research Hospital; ANKARA 06460, Turkey;

E-mail: dreminebilgi@gmail.com
} 
attention, information processing speed, executive functions, and visuo-spatial perception. Although language and intellectual functions are relatively preserved, difficulties may arise at naming some objects or identifying their functions. Visuo-spatial perception problems are mild and usually depend on the impairment of visual information processing speed and its regulation ${ }^{9,10,11,12}$.

It is known that depression affects cognitive and noncognitive activities in MS patients, and several studies have investigated the relationship between depression and cognitive dysfunction ${ }^{13,14}$. However, the correlation between depression and cognitive dysfunction remains unclear. It is thought that the treatment of depression can enhance cognitive functions ${ }^{14}$. Group psychotherapy is one of the oldest methods for the treatment of depression ${ }^{15}$. The aim of this study was to examine MS patients diagnosed with depression and cognitive dysfunction and to determine if decreasing the severity of depression via group psychotherapy improved cognitive function. The frequencies of depression and cognitive dysfunction in MS patients were tested, and those who were affected underwent psychotherapy. The effects of depression on cognitive function were measured before and after the group psychotherapy.

\section{METHOD}

A total of 108 MS patients who had applied to MS outpatient clinical trials and received a clear MS diagnosis based on the 2010 McDonald diagnostic criteria were included in this study. The protocol was approved by the Ethics Committee of the Faculty of Medicine, Firat University, and conformed to the ethical standards of the 1964 Declaration of Helsinki and its later amendments. All of the patients were thoroughly informed, and consent forms were obtained.

The inclusion criteria were as follows: (i) to be diagnosed with MS not less than 1 year; (ii) to be in remission; and (iii) to have an Expanded Disability Status Scale (EDSS) score ranging from 0.5 to 4.5 .

Patients were excluded from the study been trated with methylprednisolone within the last 3 months prior to the study or received antidepressant treatment within the previous year, were illiterate, had a substance abuse problem, or had a psychotic disorder and/or concomitant diseases that might cause cognitive dysfunction.

The subjects' disease histories and sociodemographic characteristics were determined. Each patient completed the Brief Repeatable Battery of Neuropsychological Tests (BRB-N) and the Beck Depression Inventory (BDI) administered by two neurologists.

1. BRB-N: This test was developed by the MS Cognitive Functions Study Group to evaluate cognitive function in $\mathrm{MS}^{13}$. It was modified by Rao et al. ${ }^{16}$ and consists of five tests: a. Spatial Recall Test (SPART): Evaluates visual and delayed memory. Sub-scales contain two parts: total learning (TL) and delayed recall (DR) ${ }^{17}$;

b. Symbol Digit Modalities Test (SDMT): Measures sensitivity and alertness ${ }^{18}$;

c. Paced Auditory Serial Addition Test (PASAT): Measures the progress speed of knowledge and alertness ${ }^{13}$;

d. Word List Generation Test (WLGT): Measures semantic improvement and production ${ }^{17}$;

e. Selective Reminding Test (SRT): Evaluates verbal memory. Sub-scales contain two parts: total learning (TL) and delayed recall $(\mathrm{DR})^{13}$.

2. BDI: This test consists of 21 sentence groups and was independently completed by each patient. First developed in 1961 by Beck, it utilizes a cognitive perspective and quantitatively assesses the depressive symptoms perceived by the patient. It is recommended for the screening of depression in MS as it is brief and not affected by the presence of neurological symptoms ${ }^{19}$. The Turkish version of the BDI was used in our study ${ }^{20}$. Patients were diagnosed with depression if they scored 18 or higher on the BDI.

Tests were administered to the patients by a neurologist and a neuropsychologist. The BDI was applied first in our study. Those who scored 18 and above completed a psychiatric consultation in order to detect depression. To assess cognitive impairment, the BRB-N tests (10/36 SPART, SDMT, WLGT, and PASAT) were administered. Normative data of the Turkish population has been used for the BRB-N and, as in the literature, patients performing lower than the $5^{\text {th }}$ percentile in at least two of the tests were assumed to have cognitive dysfunction ${ }^{15,21}$. We identified 15 patients with cognitive dysfunction and depression who received psychotherapy twice a month for a period of 3 months administered by two neurologists and two psychologists. Among all the patients in group psychotherapy, none were treated with antidepressants during the study period. Patients were divided into two groups, and every individual completed 45-minute sessions. All of the patients attended the six-session group psychotherapy. Tests were repeated at the end of 3 months, and patients were evaluated by a psychiatrist.

\section{Group Psychotherapy}

(i) Consciousness-raising: Patients were briefed on which cognitive functions are impaired in MS. Additionally, they were informed about psychiatric conditions affecting cognition such as depression and personality and anxiety disorders. Afterward, the possible effects of these cognitive difficulties on everyday life were shared with patients. Cognitive problems that could be identified by the patients themselves were discussed within the group sessions. In this regard, courses of action were discussed with 
a focus on problems experienced by many other MS patients.

(ii) Group Interaction: It was emphasized that the patients were not alone. Strategies to cope with their problems and to empathize were determined.

(iii) Depression and MS: Given the prevalence of depression in MS patients, the symptoms of depression were discussed. Among the patients who attended group psychotherapy, symptoms of social isolation, withdrawal, sleep problems, fear of being labeled, and denial of the illness's presence were noted. Therapeutic collaboration and group interaction were achieved via the realization that such difficulties are likely experienced by the other group members. Effects of depression on cognition and the course of MS were shared with the patients, and ways to deal with this illness were discussed.

(iv) External Support and Homework Assignments: Cognitive exercises that could easily be adapted to the daily lives of the patients were assigned as homework, and the benefits of these exercises were shared with the group in the next session.

(v) Hopefulness: Patients were assured that although cognitive impairment and depression are common in MS patients, they are treatable, and quality of life can be enhanced via therapist-doctor-patient cooperation and proper interventions.

(vi) Organization: The importance of organization and continued interaction within the framework of a patient association was emphasized.

\section{Statistical analysis}

Data obtained at the end of the study was analyzed via SPSS for the Windows 10.0 package statistics program (SPSS Inc., Chicago, IL, USA). Compliance of the measured data with the normal distribution was evaluated using one-sample Kolmogorov-Smirnov tests. One-way analysis of variance (ANOVA) testing was used to analyze the differences between the groups in terms of scores obtained from each test, while paired $t$-tests were used to evaluate the effectiveness of psychotherapy. Values obtained were expressed as the mean \pm standard error (SE). Significance level for all statistics was accepted as $\mathrm{p} \leq 0.05$.

\section{RESULTS}

Among the 108 MS patients who participated in the study, $69.4 \%(n=75)$ were female and $30.6 \%(n=33)$ were male. The average age was $36.58 \pm 1.53$ (22-62). We found that $77.8 \%(\mathrm{n}=84)$ of the MS patients had relapsing-remitting multiple sclerosis (RRMS), while $22.2 \%(n=24)$ had secondary progressive multiple sclerosis (SPMS). The average age at onset was 29.58 \pm 1.25 (Table 1).

Depression was detected in $19.5 \%$ of patients. The rates of depression in males and females were $9.1 \%(n=3)$ and $24.0 \%$ $(n=18)$, respectively. The average age of MS patients with depression was $42.00 \pm 4.48$, while the average for MS patients without depression was $35.28 \pm 1.50$. The statistical analysis indicated that age was not a significant factor for depression ( $p>0.05$ ). The illness period of MS patients with depression was $9.00 \pm 2.13$ years, and the illness period of MS patients without depression was $6.52 \pm 0.76$ years. Statistical analysis showed that although the depressed patients suffered from MS longer than patients without depression, this difference was not significant ( $\mathrm{p}>0.05$ ). The average EDSS score of MS patients with depression was $3.00 \pm 0.36$, while that of MS patients without depression was $1.88 \pm 0.22$. The $t$-test results revealed that the EDSS score of patients with depression was significantly higher than those without depression ( $\mathrm{p} \leq 0.05)$.

According to the BRB-N test results, cognitive dysfunction was detected in $41.7 \%$ of patients, including $54.6 \%$ $(n=18)$ of males and $36.0 \%(n=27)$ of females (Table 2$)$. The average age of MS patients with cognitive dysfunction was $40.67 \pm 2.60$, which was significantly higher $(p \leq 0.05)$ than that of MS patients without cognitive dysfunction (CD) which was $33.67 \pm 1.60$.

The illness period of MS patients with cognitive dysfunction was $6.60 \pm 1.14$ years compared to $7.29 \pm 0.99$ years in patients without cognitive dysfunction $(\mathrm{p}>0.05)$. The average EDSS scores of MS patients with and without cognitive dysfunction were $2.77 \pm 0.30$ and $1.62 \pm 0.23$, respectively, which was significantly different $(\mathrm{p} \leq 0.01)$. Besides, the EDSS

Table 1. Patient demographic information.

\begin{tabular}{lcccc}
\hline Patients' characteristics & Normal $(n=27)$ & $D(n=21)$ & $C D(n=45)$ & $C D+D(n=15)$ \\
\hline Age & $32.33 \pm 2.75$ & $42.00 \pm 4.48$ & $40.67 \pm 2.60$ & $18: 27$ \\
Gender (M:F) & $9: 18$ & $3: 18$ & $6.60 \pm 1.14$ & $3: 12$ \\
Duration of illness (years) & $5.54 \pm 1.24$ & $9.00 \pm 2.13$ & $2.77 \pm 0.30^{*}$ & $8.60 \pm 2.21$ \\
EDSS & $1.67 \pm 0.25$ & $3.00 \pm 0.36^{*}$ & $10.76 \pm 0.64$ & $2.90 \pm 0.20^{*}$ \\
Education (years) & $14.76 \pm 2.42^{\#, \&}$ & $13.64 \pm 3.72^{\#, \&}$ & $9.76 \pm 1.57$ \\
\hline
\end{tabular}

*Significant for the normal group $p \leq 0.05$; "Significant for the CD+D group $p \leq 0.05$; ${ }^{\star}$ Significant for the CD group $p \leq 0.05$. D: Depression; CD: Cognitive dysfunction; CD+D: Cognitive dysfunction and depression together. 
Table 2. Patients' test results.

\begin{tabular}{|c|c|c|c|c|c|c|}
\hline Groups & BDI & SPART-TL/SPART-DR & SDMT & PASAT & WLGT & SRT-TL/ SRT-DR \\
\hline Normal $(n=27)$ & $8.12 \pm 0.89$ & $17.75 \pm 6.48 / 7.23 \pm 0.65$ & $47.71 \pm 0.85$ & $52.50 \pm 6.74$ & $25.83 \pm 0.87$ & $47.75 \pm 6.48 / 7.98 \pm 2.26$ \\
\hline$D(n=21)$ & $21.06 \pm 2.22^{\star, \#}$ & $16 \pm 6.77 / 8.74 \pm 1.75^{\#}$ & $45.73 \pm 0.68^{*, \#}$ & $50.23 \pm 5.78^{*, \#}$ & $26.05 \pm 1.94$ & $46 \pm 6.77 / 7.86 \pm 1.96$ \\
\hline$C D(n=45)$ & $7.91 \pm 1.15$ & $11 \pm 3.83 * / 4.96 \pm 0.62 *$ & $22.66 \pm 0.38 *$ & $33.56 \pm 4.51 *$ & $14.68 \pm 0.74^{*}$ & $11 \pm 3.83 * / 5.86 \pm 1.28 *$ \\
\hline$C D+D(n=15)$ & $25.20 \pm 2.97 *, \#$ & $13 \pm 3.83 * / 5.13 \pm 0.25 *$ & $24.10 \pm 1.18 *$ & $24.00 \pm 9.83 *$ & $14.33 \pm 0.35 \star$ & $10 \pm 2.13 * / 4.98 \pm 1.88 *$ \\
\hline
\end{tabular}

*Significant for the normal group $p \leq 0.05$; "Significant for the CD group $p \leq 0.05$. BDI: Beck depression inventory; SPART: Spatial recall test; SDMT: Symbol digit modalities test; PASAT: Paced auditory serial addition test; WLGT: Word list generation test; SRT: Selective reminding test; D: Depression; $\mathrm{CD}$ : Cognitive dysfunction; $\mathrm{CD}+\mathrm{D}$ : Cognitive dysfunction and depression together.

scores of these patients proved to be significantly high $(\mathrm{p} \leq 0.05)$.

The effects of education were evaluated, and the results revealed that patients with cognitive dysfunction were less educated than the other two groups ( $\mathrm{p} \leq 0.05$ ).

Depression and cognitive dysfunction were comorbid in $13.9 \%(n=15)$ of patients. The distributions of CD+ depression (D) cases by sex were $2.7 \%(\mathrm{n}=3)$ of males and $11.1 \%$ $(\mathrm{n}=12)$ of females. The average patient age was $41.67 \pm 2.70$, and the average EDSS score was $2.90 \pm 0.20$. The mean test scores before and after the 3-month group psychotherapy intervention are listed in Table 3. The psychiatric evaluation suggested that fewer depressive symptoms in patients persist.

Cognitive dysfunction was detected in $41.6 \%$ of MS patients with depression. When the test scores of depressed patients were compared to those without depression, only the PASAT scores were lower than the scores of nondepressed patients $(\mathrm{p} \leq 0.05)$. When the test scores of patients with both depression and cognitive dysfunction were compared to those with only cognitive dysfunction, the scores of the Paced Auditory Serial Addition Test, Word List Generation Test, and Selective Reminding Test were lower than those of the patients with only cognitive dysfunction, although the differences were not significant. While improvement was observed in most of the tests administered after group psychotherapy, only the Paced Auditory Serial Addition Test scores increased significantly $(p \leq 0.05)$.

\section{DISCUSSION}

In this study, the rate of comorbid depression and cognitive dysfunction $(\mathrm{CD}+\mathrm{D})$ was determined in MS patients, and the effect of psychotherapy on cognitive function in those with $\mathrm{CD}+\mathrm{D}$ was assessed. The ratio of the MS patients with cormorbid depression and cognitive dysfunction was similar to the prevalence reported in the literature ${ }^{9,22}$.

In accordance with the literature, we found that MS patients' age, sex, and illness duration did not differ between the groups with and without depression, but a positive correlation with the EDSS score and depression was observed ${ }^{23}$. On the other hand, it is known that cognitive functions are affected by many factors ${ }^{24}$. Sex and illness duration did not differ between the groups with and without cognitive dysfunction. It was determined that the ages and EDSS scores of patients with cognitive dysfunction were higher than the other groups. In addition, the education duration of the cognitive dysfunction group was shorter than the other patient groups.

Seinela et al. ${ }^{25}$ compared group of MS patients with cognitive impairment to a group of MS patients without cognitive dysfunction and a healthy control group and determined that in the group with cognitive dysfunction, conscious memory performance deteriorated while unconscious memory performance was preserved. Additionally, both conscious and unconscious memory performance were preserved in the MS group without cognitive dysfunction, indicating that conscious memory was more severely affected in MS. Although it had been previously believed that recall deficits in patients MS were the primary memory dysfunction, recent studies suggest that although MS patients need more trials for learning, they can remember what they learn ${ }^{11,26}$. We found lower BRB-N scores in patients with cognitive dysfunction compared to those who were cognitively intact. Our findings indicated that our patients were especially affected in terms of attention, recall, visuo-spatial learning, and knowledge production.

Table 3. Average test scores before and after the 3-month group psychotherapy intervention.

\begin{tabular}{lcc} 
Group & CD+D (pre-psychotherapy) & CD+D (post-psychotherapy) \\
\hline Paced auditory serial addition test & $24.00 \pm 9.83$ & $50.20 \pm 6.99 *$ \\
Spatial recall test & $13 \pm 3.835 .13 \pm 0.25$ & $12 \pm 3.625 .2 \pm 1.09$ \\
Symbol digit modalities test & $24.00 \pm 1.18$ & $25.00 \pm 1.10$ \\
Word list generation test & $14.33 \pm 0.35$ & $17.60 \pm 1.86$ \\
Selective reminding test & $10 \pm 2.134 .98 \pm 1.88$ & $11 \pm 3.085 .01 \pm 1.69$ \\
Beck depression inventory & $25.20 \pm 0.97$ & $19.60 \pm 0.51 *$
\end{tabular}

*Significant compared to the pre-treatment phase p $\leq 0.05$. D: Depression; CD: Cognitive dysfunction; CD+D: Cognitive dysfunction and depression together. 
Patients with MS also experience fatigue and cognitive dysfunction, both of which can worsen depression and be worsened by depression ${ }^{27}$. Niino et al. demonstrated that MS patients had more apathy, fatigue, and depression compared to healthy persons, and decreased cognitive function was correlated with apathy and depression in Japanese patients with $\mathrm{MS}^{28}$. Hildebrandt and Eling indicated that depressive mood is at least partially related to neurodegeneration $^{29}$. Several studies have shown that the relationship between depression and cognitive impairment is best reflected by the relationship between memory and information processing speed and suggested that memory, information processing speed, and executive functions might be affected when depression is moderate $e^{14,30,31,32}$. In our study, we detected cognitive dysfunction in $41.6 \%$ of the depressed patients. Only the PASAT scores of depressed patients were significantly lower than the scores of nondepressed patients. We found that depression negatively affected functions such as awareness and information processing speed.

There are many treatment options for MS patients affected by depression ${ }^{30,33}$. Flavia et al. ${ }^{33}$ conducted studied 150 MS patients and applied a computer-assisted rehabilitation program to 20 patients who scored poorly in cognitive tests. This intervention led to improvements in patients' depression and PASAT scores at the end of 3 months. Individual cognitive-behavioral therapy, group psychotherapy, and sertraline were compared in an open trial of depressive patients with $\mathrm{MS}^{34}$. There were no significant differences between these treatments. The results of the existing studies suggest that patients with prominent memory complaints apparently unrelated to their cognitive state require screening for depression, and their cognitive impairment can improve with depression treatment ${ }^{35,36}$.

Psychotherapies with a cognitive approach, group psychotherapies, and resocialization practices can be used along with medical treatment for the treatment of depression in MS patients ${ }^{37,38}$. One study concluded that group psychotherapy in MS is an effective method in terms of the rehabilitation of somatic, emotional, and social behaviors ${ }^{39}$. We applied group psychotherapy in our study to decrease depressive symptoms in patients with MS and observed that the depressive symptoms decreased significantly and cognitive functions were slightly improved. While we observed increases in the test scores of the BDI, SPART, SDMT, PASAT, and WLGT, only the improvements on the BDI and PASAT were significant. When we evaluated the test results at the end of group psychotherapy, we observed partial improvements in terms of attention and knowledge production, whereas visuo-spatial learning and recall functions did not improve. These findings indicate that depression might affect attention and knowledge production and increase cognitive dysfunction in MS patients.

The most significant limitation of our study is the absence of a control group that did not complete a psychotherapy intervention. In additions, patients could have been able to learn the tests, especially the PASAT. Besides, group psychotherapy was short term, the number of patients was low, and the tests were not repeated after each therapy session. On the other hand, we did not detect any correlation between patient's use of MS drugs and their depression level. Some studies have found that interferon treatment may lead to depression in $\mathrm{MS}^{22}$. As no changes were made to the patients' medicine regimens during the psychotherapy period, we do not think that drug treatments affected the results of our study.

Our results show that group psychotherapy reduced depression severity. This decrease was associated with positive results in terms of patients' attention and knowledge production. It is known that cognitive functions are variable depending on many factors. Our findings suggest that greater depression severity can increase cognitive dysfunction. We conclude that the treatment of depression with group psychotherapy might decrease the severity of cognitive dysfunction in MS patients. Larger studies are needed to assess the effects of depression on cognitive function in MS and validate our conclusions.

\section{References}

1. Peterson LK, Fujinami RS. Inflammation, demyelination, neurodegeneration and neuroprotection in the pathogenesis of multiple sclerosis. J Neuroimmunol. 2007;184(1-2):37-44. http://dx.doi.org/ 10.1016/j.jneuroim.2006.11.015

2. Figved N, Klevan G, Myhr KM, Glad S, Nyland H, Larsen JP et al. Neuropsychiatric symptoms in patients with multiple sclerosis. Acta Psychiatr Scand. 2005;112(6):463-8. http://dx.doi.org/10.1111/j.16000447.2005.00624.x

3. Bilgi E, Özdemir HH, Bulut S. Multipl Sklerozlu Hastalarda Depresyon ve Kognitif Fonksiyon Bozukluğu Sıklığının Belirlenmesi. Türk Nör Der. 2013;19(1):11-4. 10.4274/Tnd.15045

4. Schiffer RB. Disturbances of affect. In: Rao SM, editor. Neurobehavioral aspects of multiple sclerosis. Oxford: Newyork, 1990.
5. Tuncer N. Multipl sklerozlu olgularda kognitif fonksiyon bozuklukları. Türkiye Klinikleri. 2006;26(5):559-64.

6. Chiaravalloti ND, DeLuca J. Cognitive impairment in multiple sclerosis. Lancet Neurol. 2008;7(12):1139-51. http://dx.doi.org/ 10.1016/S1474-4422(08)70259-X

7. Winkelmann A, Engel C, Apel A, Zettl UK. Cognitive impairment in multiplesclerosis. J Neurol. 2007;254(2 Suppl):II35-42. http://dx.doi. org/10.1007/s00415-007-2010-9

8. Rogers IM, Panegyres PK. Cognitive impairment in multiple sclerozis evidence-based analysis and recommendations. J Clin Neurosci. 2007;14(10):919-27. http://dx.doi.org/10.1016/j.jocn.2007.02.006

9. Portaccio E, Goretti B, Zipoli V, Siracusa G, Sorbi S, Amato MP. A short version of Rao's Brief Repeatable Battery as a screening tool for 
cognitive impairment in multiple sclerosis. Clin Neuropsychol. 2009;23(2):268-75.

10. Bobholz JA, Rao SM. Cognitive dysfunction in multiple sclerosis: a review of recent developments. Curr Opin Neurol. 2003;16(3):283-8. http://dx.doi.org/10.1097/00019052-200306000-00006

11. Rao SM. Neuropsychology of multiple sclerosis. Curr Opin Neurol. 1995;8 (3):216-20. http://dx.doi.org/10.1097/00019052-199506000-00010

12. Kujala P, Portin R, Ruutiainen J. Language functions in incipient cognitive decline in multiple sclerosis. J Neurol Sci. 1996;14(1-2):79-86. http://dx.doi.org/10.1016/0022-510X(96)00146-3

13. Rao SM. A manual for the Brief Repeatable Battery of Neuropsychological Tests in multiple sclerosis. Milwaukee: Medica College of Wisconsin; 1990.

14. Arnett PA, Barwick FH, Beeney JE. Depression in multiple sclerosis: review and theoretical proposal. J Int. Neuropsychol Soc. 2008;14(5):691-24. http://dx.doi.org/10.1017/S1355617708081174

15. Fuchs CZ, Rehm LP. A self-control behavior therapy program for depression J Consult Clin Psychol. 1977;45(2):206-15.

16. Rao SM, Leo GJ, Bernardin L, Unverzagt F. Cognitive dysfunction in multiple sclerosis. I. Frequency, patterns and prediction. Neurology. 1991;41(5):685-91. http://dx.doi.org/10.1212/WNL.41.5.685

17. Achiron A, Polliack M, Rao SM, Barak Y, Lavie M, Appelboim N et al. Cognitive patterns and progression in multiple sclerosis: construction and validation of percentile curves. J Neurol. 2005;76(5):744-9. http://dx.doi.org/10.1136/jnnp.2004.045518

18. Benedict $\mathrm{RH}$, Duquin JA, Jurgensen S, Rudick RA, Feitcher J, Munschauer FE et al. Repeated assessment of neuropsychological deficits in multiple sclerosis using the Symbol Digit Modalities Test and the MS Neuropsychological Screening Questionnaire. Mult Scler. 2008;14(7):940-6. http://dx.doi.org/10.1177/1352458508090923

19. Benedict RH, Fishman I, McClellan MM, Bakshi R, WeinstockGuttman B. Validity of the Beck Depression Inventory-Fast Screen in multiple sclerosis. Mult Scler. 2003;9(4):393-6. http://dx.doi.org/ 10.1191/1352458503ms902oa

20. Akdemir A, Türkçapar MH, Orsel SD, Demirergi N, Dag I, Ozbay MH. Reliability and validity of the Turkish version of the Hamilton Depression Rating Scale. Compr Psychiatry. 2001;42(2):161-5. http://dx.doi.org/10.1053/comp.2001.19756

21. Bingöl A, Yıldız Ș, Topçular B, Tutuncu M, Demirci NO, Uygunoglu U et al. Brief repeatable battery (BRB) Turkish Normative Data [abstract]. Eur J Neurol. 2012:9(Suppl1):558. [Poster presentation at 16th Congress of the European Federation of Neurological Societies; 2012; Stockholm, Sweden].

22. Soyuer F, Ünalan D, Mirza MM. MS’te Depresif Semptomlar. Turk Norol Derg. 2010;16:31-5

23. Mendes MF, Tilbery CP, Balsimelli S, Moreiria MA, Barão-Cruz AM Depression in relapsing-remitting multiple sclerosis. Arq Neuropsiquiatr. 2003;61(3A):591-5. http://dx.doi.org/10.1590/S0004$282 \times 2003000400012$

24. Topçular B, Özcan ME, Kurt E, et al. Cognitive impairment in relapsing-remitting multiple sclerosis. Noropsikiyatri Ars. 2012;49:178-82.
25. Seinelã $A$, Hämäläinen $P$, Koivisto $M$, Ruutiainen J. Conscious and unconscious uses of memory in multiple sclerosis. J Neurol Sci. 2002;198(1-2):79-85. http://dx.doi.org/10.1016/S0022-510X(02)00082-5

26. Bagert B, Camplair P, Bourdette D. Cognitive dysfunction in multiple sclerosis: natural history, pathophysiology and management. CNS Drugs. 2002;16(7):445-55. http://dx.doi.org/10.2165/00023210200216070-00002

27. Kinsinger SW, Lattie E, Mohr DC. Relationship between depression, fatigue, subjective cognitive impairment, and objective neuropsychological functioning in patients with multiple sclerosis. Neuropsychology 2010;24(5):573-80. http://dx.doi.org/10.1037/a0019222

28. Niino M, Mifune N, Kohriyama T, Mori M, Ohashi T, Kawachi I et al. Apathy/depression, but not subjective fatigue, is related with cognitive dysfunction in patients with multiple sclerosis. BMC Neurol. 2014;14(1-3):3. http://dx.doi.org/10.1186/1471-2377-14-3

29. Hildebrandt H, Eling P. A longitudinal study on fatigue, depression, and their relation to neurocognition in multiple sclerosis. J Clin Exp Neuropsychol. 2014;36(4):410-7. http://dx.doi.org/10.1080/13803395. 2014.903900

30. Siepman TA, Janssens AC, Koning I, Polman CH, Boringa JB, Hintzen $\mathrm{RQ}$. The role of disability and depression in cognitive functioning within 2 years after multiple sclerosis diagnosis. J Neurol. 2008;255(6):910-6. http://dx.doi.org/10.1007/s00415-008-0814-x

31. Chiaravalloti ND, DeLuca J. Cognitive impairment in multiple sclerosis. Lancet Neurol. 2008;7(12):1139-51. http://dx.doi.org/ 10.1016/S1474-4422(08)70259-X

32. Ünal A, Sütlaș N, Kușçu DY, Kırbaș D. Relationship between cognitive impairment and disease duration in multiple sclerosis. J Neurol Sci. 2000;17:3.

33. Mattioli F, Stampatori C, Zanotti D, Parrinello G, Capra R. Efficacy and specificity of intensive cognitive rehabilitation of attention and executive functions in multiple sclerosis. J Neurol Sci. 2010;288(1-2):101-5. http://dx.doi.org/10.1016/j.jns.2009.09.024

34. Siegert RJ, Abernethy DA. Depression in multiple sclerosis: a review. J Neurol Neurosurg Psychiatry. 2005;76(4):469-75. http://dx.doi.org/ 10.1136/jnnp.2004.054635

35. Foong J, Rozewich L, Quaghebeur G, Thompson AJ, Miller DH, Ron MA. Neuropsychological deficits in multiple sclerosis after acute relapse. J Neurol Neurosurg Psychiatry. 1998;64(4):529-32. http://dx.doi.org/10.1136/jnnp.64.4.529

36. Jønsson A, Korfitzen EM, Heltberg A, Ravnborg MH, Byskov-Ottosen E. Effects of neuropsychological treatment in patients with multiple sclerosis. Acta Neurol Scand. 1993;88(6):394-400. http://dx.doi.org/ 10.1111/j.1600-0404.1993.tb05366.x

37. Minden SL, Schiffer RB. Affective disorders in multiple sclerosis: reviews and recommendations for clinical research. Arch Neurol. 1990;47(1):98104. http://dx.doi.org/10.1001/archneur.1990.00530010124031

38. Mohr DC, Hart SL, Goldberg A. Effects of treatment for depression on fatigue in multiple sclerosis. Psychosom Med. 2003;65(4):542-7. http://dx.doi.org/10.1097/01.PSY.0000074757.11682.96

39. Mazaheri M, Fanian N, Zargham-Boroujeni A. Experiences of patients with multiple sclerosis from group counseling. Iran J Nurs Midwifery Res. 2001:16(2):181-90. 